\title{
The Relation between Performance and Flows of Mutual Funds: Case of the Croatian Fund Market
}

\author{
Darko Brborovic ${ }^{1}$, Petra Posedel ${ }^{2}$ \\ ${ }^{1}$ OTP Invest, Zagreb, Croatia \\ ${ }^{2}$ Department of Mathematics and Statistics, Zagreb School of Economics and Management, Zagreb, Croatia \\ Email: darko.brborovic@otpinvest.hr, pposedel@zsem.hr
}

Received 25 August 2014; revised 16 September 2014; accepted 6 October 2014

Copyright $@ 2014$ by authors and Scientific Research Publishing Inc.

This work is licensed under the Creative Commons Attribution International License (CC BY). http://creativecommons.org/licenses/by/4.0/

(c) (i) Open Access

\begin{abstract}
With pre 2008 euphoria and present depression, inflows to open investment funds and outflows from it shaped general market conditions on the Croatian fund market. This article studies the relationship between performance of open ended investment funds and inflows (outflows) to them on Croatian funds data in an environment without long fund data history, with small number of funds and relatively illiquid underlying equity market. The results suggest that the driving forces behind funds' flows encompass the combined influence of present month fund's performance and persistency of past performances. At the end of our analysis we test the significance of the introduced explanatory variables on the data sets that include data for each particular fund. The significance of the introduced explanatory variables varies among different funds, although a general level of the explanatory power is maintained on average.
\end{abstract}

\section{Keywords}

Asset under Management, Mutual Fund Performance, Fund Flows, Linear Regression, Emerging Economies

\section{Introduction}

In recent years the Croatian fund market passed through very turbulent times, with pre 2008 euphoria and present depression. Inflows to open investment funds and outflows from it followed, but also shaped general market conditions. In this article we want to test the relationship between performance of open ended investment funds registered in Croatia and inflows (outflows) to them. 
General literature on this subject is relatively rich, with early performance-flow relationship analyzed in Chevalier \& Ellison [1], Sirri \& Tufano [2] and Ippolito [3]. Those authors analyzed the relationship among various characteristics of funds (performance, age, fees, size) and were trying to estimate their influence on inflows to open ended funds (mutual funds, or in this article just funds). Additionally, they found out that past performance is an important determinant of fund flows, although the relationship is not straightforward. Findings of those authors indicate that the best performing funds tend to attract more inflows relative to other funds and in fund literature that characteristics is often referred as a convex relationship between performance of funds and inflows to them. However, Spiegel \& Zhang [4] indicate that the relationship between performance and flows is linear if we measure flows into funds by market share. As funds flow data are rich in many aspects, lots of researchers used those data to analyze different aspects of fund performance, like Chen et al. [5], connecting fund outflows and liquidity level of its assets. In Huang et al. [6] for example, it tried to develop analytical models that would describe the relationship between performance and flows of the fund. Most of those articles used US fund data from obvious reasons. It is the most developed market with the longest data history and good data bases. However in Ferreira et al. [7] data from 27 countries were analyzed and some of the effects from the US fund data were not found in all other countries. Also, some country characteristics may explain fund performance. It is worth to mention that lots of authors tried to analyze managerial abilities of fund managers, but this issue will not be addressed in this work, because of the lack of publicly available benchmarks for funds that we are taking into consideration.

We are interested in testing some results from literature on the Croatian funds' data in an environment without long fund data history, with small number of funds and a relatively illiquid underlying equity market. There were no many studies on Croatian and other South and Eastern European (SEE) fund markets and to our knowledge the only one is Podobnik et al. [8]. However, authors in that article focus on performance analysis of funds on selected SEE markets.

In Section 2, description of the Croatian open investment funds market is given, in order to explain the context of data we analyze. Also, we describe the type of data we are using. In Section 3 we test the basic relationship between performance of the selected funds and their flows following Sirri \& Tufano [2]. In Section 4, we give some refinements of our analysis. Finally, conclusions and guidelines for future research are given in Section 5.

\section{Market and Data}

The Croatian economy is a transitional one and started to implement market reforms in the last decade of the 20th century. The financial system is traditionally dominated by banks and most of citizens' savings were channeled either to bank deposits or real estate. In such environment, capital markets in Croatia were not developing quickly and only at the end of the last century meaningful trading on Zagreb Stock Exchange started to emerge.

The Croatian funds market is young one with first open investment funds that started to operate in 1999: The first successful funds were money market funds. In 2001: and 2002: equity and balanced funds started to appear, but most of them invested their assets on developed markets in an unfortunate time of post dot-com bubble. A notable exception was the fund RBA Balanced that chose a different path and started to invest in Croatian equities. The format of a balanced (mixed) fund was a rational choice in the presence of an illiquid market, but with a lot of neglected stocks. Also, the beginning of that fund coincided with the start of the second pillar obligatory pension fund in Croatia which subsequently raised the liquidity of the market. We are mentioning this particular fund as its successful growth path is relevant for further development of the Croatian funds market. Namely, in the next few years several other balanced funds, as a proxy for equity investments on the Croatian equity market, were launched from other asset management companies. Encouraged by the success of such funds and interest of investors for them, asset management companies started to launch pure equity funds that invested on the Croatian, but also on other regional markets (Slovenian, Serbian, Macedonian and some other). A quick rise of assets under management in balanced and equity funds haven't lasted long and after the global financial crisis that made full impact in 2008 assets under management in those funds have fallen dramatically. It is interesting to note that until today bond funds in Croatia never reached any meaningful size and stayed the smallest market segment with market share of some $5 \%, 6 \%$.

For the purpose of our analysis we are looking only at balanced and equity funds segments. The main reason is that those funds offer meaningful magnitude and difference of their performances (in contrast to money mar- 
ket funds) and with them it is possible to evaluate the impact of past performance on flows (in or out) of open investment funds. At the market highs and in 2009 and 2010 there were more than 70 different balanced and equity funds on the Croatian fund market. At that time, prior to joining of Croatia to EU in 2013, majority of investors in those funds were Croatian investors. Therefore, funds data are reflecting the behavior of a relatively closed market. Of course, global events made significant impact on the Croatian economy and capital markets and we can note that the Croatian GDP is falling since 2009. To show aggregate development of assets under management in balanced and equity funds in Croatia, yearly data for assets under management in both categories is presented in Figure 1. Numbers are in $\mathrm{HRK}^{1}$ million ${ }^{2}$.

Those data include not only retail flows but also some institutional flows from insurances and pension funds based in Croatia. Furthermore, from Figure 1 one can suppose that not all funds survived bust part of the cycle and it is indeed so. Several funds fell with assets under management on insignificant levels and some were even closed/merged in the last couple of years. We cannot use data of all funds for our analysis, since some funds fell on the level of seed money and no outflows or inflows were recorded for a few years. Consequently, no relationship with performance could be established. Consolidation of the Croatian fund industry is underway and it is still not finished.

We took into account developments on the fund market when we were selecting funds for our analysis. We choose to include funds that at the end of 2012 had assets under management greater than 10 million kunas (all of them at some point of time were larger than 100 million kunas). We also include two funds that ceased to exist in 2012; but were relatively large when they were terminated or merged with other funds. Finally, we choose those funds where we had five years or more of monthly data and we finished with 21 equity and balanced funds that were existing since 2002 to 2007. The intention was to include not only the falling phase of the fund industry, but the raising one too. That is a reason why we haven’t included few funds that were launched after 2008: Those funds haven't succeed to attract any meaningful assets under management and their investor base is very low. For the sake of completeness we are naming all the funds we analyze: Aureus equity, Erste Adriatic Equity, Erste Balanced, FIMA Equity, HI Balanced, HI Growth, HPB Dionicki, HPB Dynamic, HPB Global, Ilirika JIE, KD Victoria, OTP Uravnotezeni, PBZ equity, PBZ Global, PBZ I-Stock, RBA balanced, RBA Central Europe, ZB Aktiv, ZB euroaktiv, ZB Global and ZB Trend.

In this article we are looking at monthly funds data for prices of the fund units and assets under management for each fund ${ }^{3}$. For the statistical analysis we use the software package R.

\section{The Referent Regression Model}

Although in asset management it is usual, even obligatory, to put a disclaimer that past performance is not a guarantee of future performance, every asset manager would notice that good performance of the fund attracts

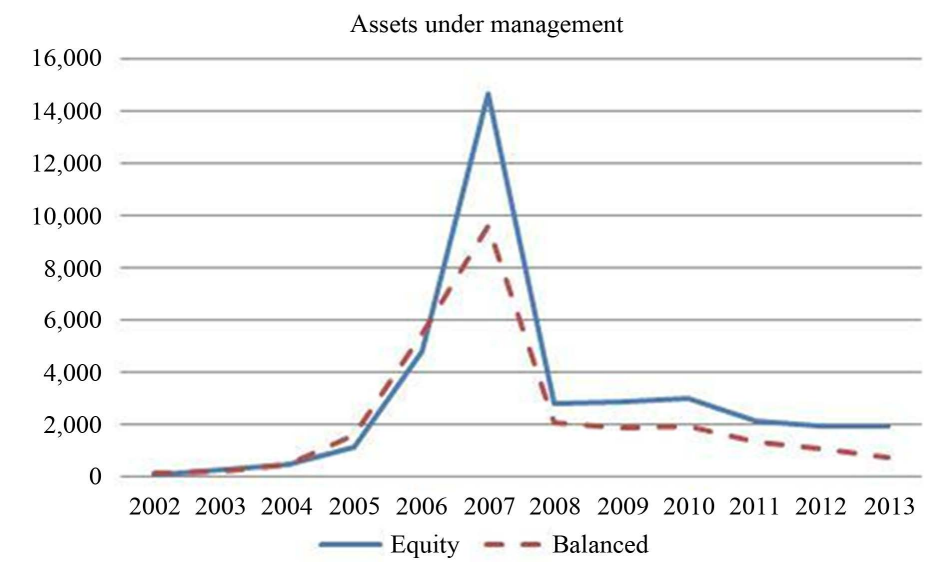

Figure 1. Yearly data on assets under management (end of year).

\footnotetext{
${ }^{1} \mathrm{HRK}$ is abbreviation for Croatian currency kuna with value of around 7, 5 kunas for one euro.

${ }^{2}$ Data are collected from the Croatian market regulator HANFA web site.

${ }^{3}$ Data were in large part obtained from the HANFA's web site, but some older data were obtained directly from asset management companies.
} 
money into the fund and losses are causing withdrawals from the fund. Certainly there is a loop feedback between performance of the fund and flows in it, but we would conjecture that still it is performance that drives interest for funds and not vice versa. Therefore, we would like to find some statistical significance in the relationship between funds' performance and flows of the fund. As a reference for our analysis we choose Sirri \& Tufano [2], where interesting explanatory variables for fund flows are introduced, focusing on the relative performance of the funds to other comparable funds. We believe that lot of useful information about fund flows is hidden in previous funds performances and, as we will see later, in historical flow data. Other independent variables used in Sirri and Tufano [2] are fees of the funds, asset in the funds and standard deviation of the performances of the funds.

Using the fee structure of funds as a variable in their analysis, Sirri \& Tufano [2] argue that larger fees would allow larger marketing efforts of the fund managers. Even if all funds in our case have quite large management fees, being all above $2 \%$ per annum, marketing efforts were never pronounced on the Croatian market. High fees would also allow for larger sales fees to distributors of funds, but we cannot access incentive schemes data for funds we are looking for in our analysis. As there is not much differentiation among fund fees, we choose not to include that variable in our analysis. There is also no style differentiation among the funds we are analyzing (growth, value and similar), so we couldn't stratify our data on that factor either. Therefore, we try to measure the effect of past performance, relative performance, size of the funds, their age, i.e. time passed since inception, and riskiness on inflows and outflows from funds.

With $N A V_{i, t}$ we denote the net asset value of fund $i, i=1, \cdots, 21$, at time $t$, where time is counted on monthly level. Net Asset Value (NAV) of the fund is a precise definition of assets in fund on any given date. We denote with $P U_{i, t}$ the price of the unit of the $i$-th fund in time $t$ (month). Price of the unit is the value of assets in the fund divided by total number of units issued in that fund ${ }^{4}$. Performance of fund $i$ in time $t$ will be denoted by $\operatorname{Perf}_{i, t}$ and is calculated as

$$
\operatorname{Perf}_{i, t}=\frac{P U_{i, t}}{P U_{i, t-1}}-1
$$

To calculate net flow to the fund (or out of it) we need to "clear" monthly NAV data from fund performance. Therefore we will calculate the net inflow (outflow) to fund $i$ in time t by

$$
\text { Flow }_{i, t}=\frac{N A V_{i, t}-N A V_{i, t-1} *\left(1+\operatorname{Perf}_{i, t}\right)}{N A V_{i, t-1}}
$$

For each of the fund data we are looking at, we get a sequence of performances in time $t$ and flow data calculated as above. In the next step we merged data for all funds in one sequence, but for every fund we excluded the first 12 monthly data. The reason for that exclusion is that we wanted to keep a comparable data set for all subsequent analyzes and in some instances we will need a 12-month history period to calculate some dependent variables. The dependent variable, the one we want to explain with other variables, is Flow. By merging our data we finished with 1859 monthly fund data and on that data set we started our analysis. We want to point out that the analysis is therefore finished with data for 21 funds sorted into rows and the number of rows for different funds is generally different as they have different number of months since their inception. Therefore, the time index depends on the fund we are looking at and thus the time index should have subindex $t_{i}^{5}$.

The first independent variable we are looking at is the age of each fund. Previous literature like Chevalier \& Ellison [1] noticed that older funds are less sensitive to recent performances. As the data is related to relatively old funds we haven't expected much differentiation among funds on that variable, but we included it into the regression analysis to check its overall significance. The next independent variable we are looking at is net assets of the fund in time $t-1$, but with logarithm taken. Most of previous analysis of fund data indicated that fund inflows are negatively affected by fund size which can be explained by liquidity constraints of the underlying market(s). In Ferreira et al. [7] authors found out that such an effect is not universally present and we want to analyze whether the Croatian data will show that effect. We also included standard deviation of each fund performance data in previous 12 months as a risk measure of fund performances and we denote it as $\operatorname{STD}_{i, t}$ (stan-

\footnotetext{
${ }^{4}$ The analysis focuses at open ended investment funds only as mentioned before.

${ }^{5}$ In both previous definitions and in definitions and formulae from now on there should not be any confusion if we omit the subindex. For a reader's convenience, we will use the subindex $t_{i}$ for a time index in the regression Equation (3).
} 
dard deviation of 12 previous monthly performances of fund $i$ in time $t$ ).

As mentioned in the Introduction, fund data literature indicates that inflows to funds are more sensitive to outstanding performances then to poor ones. We analyze that characteristic on the Croatian fund data in the following way. First, we calculate the relative performance rank, $\operatorname{Rank}_{i, t}$ for each of our fund monthly data, based on the sequence $\operatorname{Perf}_{i, t}$. More precisely, all monthly fund data are sorted by the performance variable to obtain the rank of each monthly data set and then divide those ranks by the number of data to obtain the relative rank. The rank variable ranges from 0 to 1 . In the next step we divide rank values into quintiles based on performance. So in the first (bottom) quintile are grouped the worst performance fund data and in last (high) quintile are the best performance fund data. We merged three middle quintiles into one category to keep number of variables smaller. Following Sirri \& Tufano [2] we define three new variables $\operatorname{LowPerf}_{i, t}, \operatorname{MidPerf}_{i, t}$ and $\operatorname{HighPerf}_{i, t}$. LowPerf $f_{i, t}$ variable is defined as min( $\left.\operatorname{Rank}_{i, t-1}, 0.2\right)$, MidPerf $_{i, t}$ variable is defined as $\min \left(\operatorname{Rank}_{i, t-1}-\operatorname{LowPerf}_{i, t}, 0.6\right)$ and finally $\operatorname{HighPerf}_{i, t}$ variable is defined as

$$
\text { Rank }_{i, t-1}-\text { LowPerf }_{i, t}-\text { MidPerf }_{i, t} \text {. }
$$

With independent variables defined as above, we regress the Flow variable as a dependent variable to these variables. We index our variables with $i$, as a fund enumerator, and $t_{i}$ for time (months) enumerator to emphasize that we have different number of data points for each fund $i$. Consequently, we analyze the following regression:

$$
\begin{aligned}
\text { Flow }_{i, t_{i}}= & \alpha_{0}+\alpha_{1} * \ln \left(N A V_{i, t_{i}-1}\right)+\alpha_{2} * \operatorname{STD}_{i, t_{i}}+\alpha_{3} * \operatorname{LowPerf}_{i, t_{i}} \\
& +\alpha_{4} * \operatorname{MidPerf}_{i, t_{i}}+\alpha_{5} * \operatorname{HighPerf}_{i, t_{i}}
\end{aligned}
$$

In Table 1 we present results of this regression under column A with analogous regression equations for col-

\begin{tabular}{|c|c|c|c|}
\hline Independent variable & A & B & $\mathrm{C}$ \\
\hline \multirow[t]{2}{*}{ Intercept } & $0.0924^{* *}$ & $0.1170^{* * *}$ & $0.0998^{* *}$ \\
\hline & $(0.005)$ & $(0.000)$ & $(0.008)$ \\
\hline \multirow[t]{2}{*}{$\operatorname{Ln}(N A V)$} & $-0.0052^{* *}$ & $-0.0046^{* *}$ & $-0.0050^{* *}$ \\
\hline & $(0.002)$ & $(0.004)$ & $(0.002)$ \\
\hline \multirow[t]{2}{*}{ St. dev. } & $-0.5968^{* * *}$ & $-0.6631^{* * *}$ & $-0.6020^{* * *}$ \\
\hline & $(0.000)$ & $(0.00)$ & $(0.000)$ \\
\hline \multirow[t]{2}{*}{ LowPerf } & 0.05303 & $0.1092^{*}$ & $0.1932^{*}$ \\
\hline & (0.323) & (0.039) & $(0.046)$ \\
\hline \multirow[t]{2}{*}{ MidPerf } & $0.07291^{* * *}$ & $0.0565^{* * *}$ & $0.0711^{* * *}$ \\
\hline & $(0.000)$ & $(0.000)$ & $(0.000)$ \\
\hline \multirow[t]{2}{*}{ HighPerf } & $0.2553^{* * *}$ & $0.2474^{* * *}$ & $0.3128^{* * *}$ \\
\hline & $(0.000)$ & $(0.000)$ & $(0.000)$ \\
\hline \multirow[t]{2}{*}{ Age } & & $-0.0077^{* * *}$ & $-0.0073^{* * *}$ \\
\hline & & $(0.000)$ & $(0.000)$ \\
\hline \multirow[t]{2}{*}{ Performance (t-1) } & & & -0.2654 \\
\hline & & & $(0.079)$ \\
\hline \multirow[t]{2}{*}{ Performance (t-2) } & & & $0.2570^{* * *}$ \\
\hline & & & $(0.000)$ \\
\hline Adjusted $R^{2}$ & 0.1046 & 0.1447 & 0.1585 \\
\hline
\end{tabular}
umns B and C. So, in the second regression, named B, a new variable Age, representing the age of the fund, was added. 
Below the value of each coefficient, its p-value is given. In the last row adjusted $R^{2}$ values are given and the results are similar as in Sirri \& Tufano [2]. Namely, coefficients of variables Standard deviation, MidPerf and HighPerf are significantly different from zero as well as the coefficient of logarithm of assets in funds and Age in the case of the second regression. Coefficients of $\ln (N A V)$ and Age are both negative as it was noted in the literature on this topic.

It may be noted that we used no straightforward performance variable to explain Flow variable which is slightly strange if we started with the claims that flows to funds are, at least partially, determined by performance data. The problem may be that some simple ideas/relationships are not good enough to increase explanatory power of regression variables. As an example in column $\mathrm{C}$ we present regression results in which we added variables $\operatorname{Perf}_{i, t-1}$ and $\operatorname{Perf}_{i, t-2}$, i.e. performances of the funds in month before the referenced month and two months before it. We see that the explanatory power of those two new variables is not significant, and we may suppose that slightly higher significance of performance in time $t-2$ is rather spurious than a systematic characteristics of flow-performance relationship.

In the next section we will try to explore in more details how performance of the fund influences fund's flow. Also, we will add some new variables that can explain more variability in the Flow variable (measured by adjusted $R^{2}$ ).

\section{Refinements of the Model}

The first idea for improving the explanatory power of performance data on the Flow variable would be, as it was already done in Chevalier \& Ellison [1] for example, to look at differences of performances of funds in month $t$ with some stock market benchmark. In our case, the most appropriate benchmark would be the Zagreb stock exchange value weighted benchmark CROBEX. We tried to regress such variables but results were not satisfactory and we are not presenting them here. We can conjecture that explanatory power of such differences is not large because the benchmark is maybe not appropriate, but lack of the official benchmarks for funds we are looking at are preventing further progress in that direction. Also, we may note that investors on the Croatian market are not used to look at the performance of the asset manager versus some benchmark, but are evaluating performances on the absolute return basis.

We return back on fund performance data and we suppose that it is not monthly performance that determines investors' interest for some funds, but some persistency of the performance. In other words, we supposed that several months of good performances (and similar for bad ones) may influence flows to fund. We are looking at 6 months and 12 months performances and its relation to flow data. More precisely, we de ne new variables $\operatorname{Perf} 12_{i, t}$ by

$$
\operatorname{Perf} 12_{i, t}=\prod_{i=t-12}^{t-1}\left(1+\operatorname{Perf}_{i, t}\right)-1
$$

and analogously $\operatorname{Perf} 6_{i, t}$. Also, we look at the most recent performances $\operatorname{Perf}_{i, t}$ and $\operatorname{Perf}_{i, t-1}$ to test whether flows to funds are more sensitive to the most recent performance data. Of course, by including performance in $\mathrm{t}$ we are diminishing predictive power of the model, but we are aiming to increase its explanatory value. Result of the regression with those three new explanatory variables $\left(\operatorname{Perf}_{i, t}, \operatorname{Perf} f_{i, t-1}\right.$ and $\left.\operatorname{Perf} 12_{i, t}\right)$ are presented in Table 2 under column D.

As we can see from Table 2, the new independent variables are statistically significant and are increasing the explanatory power of the model. We may note that 6 months previous performance is not giving any new information and its explanatory power is lower than a presented one. Also, we tried to include an exogenous variable in the calculation of $\operatorname{Perf} 12_{i, t}$ by subtracting from it some short term deposit rates available to investors. The idea was to check whether some basic measure of relative performance of cumulative past performance over a short rate would give better measure than absolute cumulative performance. However, we obtained similar results and by choosing a simpler variable over a more complex one, we present only result presented in column D.

In the next step we turn to flow data. Namely, as noted in Cashman et al. [9], flows to funds are persistent by themselves. That means that inflows to the funds are showing persistency-positive inflows are followed by new inflows and vice versa-outflows are more likely to be followed by new outflows. We want to check the importance of previous monthly flow data on present flows. We defined new variables $F l o w 1_{i, t}$, Flow $3_{i, t}$ and Flow6 $_{i, t}$ by 
Table 2. Regression results on merged fund data.

\begin{tabular}{|c|c|c|}
\hline Independent variable & $\mathrm{D}$ & $\mathrm{E}$ \\
\hline \multirow[t]{2}{*}{ Intercept } & $0.1449^{* * *}$ & $0.1298^{* * *}$ \\
\hline & $(0.000)$ & $(0.000)$ \\
\hline \multirow[t]{2}{*}{ Performance (t) } & $0.5329^{* * *}$ & $0.4970^{* * *}$ \\
\hline & $(0.000)$ & $(0.000)$ \\
\hline \multirow[t]{2}{*}{ Performance (t-1) } & $-0.4097^{* *}$ & $-0.3511^{* *}$ \\
\hline & $(0.004)$ & $(0.009)$ \\
\hline \multirow[t]{2}{*}{ Performance 12 months } & $0.0834^{* * *}$ & $0.0439^{* * *}$ \\
\hline & $(0.004)$ & $(0.000)$ \\
\hline \multirow[t]{2}{*}{$\operatorname{Ln}(N A V)$} & $-0.0082^{* * *}$ & $-0.0073^{* * *}$ \\
\hline & $(0.000)$ & $(0.000)$ \\
\hline \multirow[t]{2}{*}{ Age } & $-0.0044^{* * *}$ & $-0.0027^{* * *}$ \\
\hline & $(0.000)$ & $(0.001)$ \\
\hline \multirow[t]{2}{*}{ St. dev. } & -0.1301 & -0.0915 \\
\hline & $(0.244)$ & $(0.392)$ \\
\hline \multirow[t]{2}{*}{ LowPerf } & 0.1101 & 0.0522 \\
\hline & $(0.228)$ & $(0.551)$ \\
\hline \multirow[t]{2}{*}{ MidPerf } & $0.0621^{* * *}$ & $0.0502^{* * *}$ \\
\hline & $(0.000)$ & $(0.001)$ \\
\hline \multirow[t]{2}{*}{ HighPerf } & $0.2989^{* * *}$ & $0.2047^{* *}$ \\
\hline & $(0.000)$ & $(0.002)$ \\
\hline \multirow[t]{2}{*}{ Flow in prev. month } & & $0.1349^{* * *}$ \\
\hline & & $(0.000)$ \\
\hline \multirow[t]{2}{*}{ Flow in last 3 months } & & $0.0627^{* * *}$ \\
\hline & & $(0.000)$ \\
\hline Adjusted $R^{2}$ & 0.2504 & 0.3123 \\
\hline \multicolumn{3}{|c|}{ Flow $_{i, t}=$ Flow $_{i, t-1}$} \\
\hline \multicolumn{3}{|c|}{ Flow $_{i, t}=\prod_{i=t-3}^{l-1}\left(1+\right.$ Flow $\left._{i, t}\right)-1$} \\
\hline
\end{tabular}

We test the significance of previous flows up to six months in the past, since results from Cashman et al. [9] indicate that this connection weakens when we go further in the past.

Results of the regression with variables Flow $1_{i, t}$ and Flow $3_{i, t}$ are shown in Table 2 under column E. We may note that both variables are statistically significant, whereas Flow6 $6_{i ; t}$ is not and is therefore not shown. Inclusion of those two variables increased the explanatory power of the model. Interestingly though, standard deviation is not important any more and significance of variables LowPerf, MidPerf and HighPerf is decreasing.

We finished our regression model with quite a lot independent variables. In order to decrease the number of variables, we apply the Aikake's information criterion on our last regression model. In Table 3 we present regression results with reduced number of independent variables under column F. Finally, we excluded 18 most extreme Flow data from our merged data set (9 largest inflows and 9 largest outflows) and present results of the same regression but on that reduced data set (1\% of the data excluded) in column $\mathrm{G}$. 
Table 3. Regression results on merged fund data.

\begin{tabular}{ccc}
\hline Independent variable & $\mathrm{F}$ & $\mathrm{G}$ \\
\hline Intercept & $0.1350^{* * * *}$ & $0.0917^{* * *}$ \\
Performance (t) & $(0.000)$ & $(0.000)$ \\
Performance 12 months & $0.4810^{* * *}$ & $0.4206^{* * *}$ \\
& $(0.000)$ & $(0.000)$ \\
Ln(NAV) & $0.0492^{* * *}$ & $0.0396^{* * *}$ \\
& $(0.000)$ & $(0.000)$ \\
Flow in prev. month & $-0.0069^{* * *}$ & $-0.0047^{* * *}$ \\
& $(0.000)$ & $(0.000)$ \\
Flow in last 3 months & $0.1460^{* * *}$ & $0.0747^{* *}$ \\
& $(0.000)$ & $(0.001)$ \\
Adjusted $R^{2}$ & $0.0702^{* * *}$ & $0.0883^{* * *}$ \\
\hline
\end{tabular}

As it can be seen from Table 3, performance is an important explanatory variable for the flows of the funds. However, most of the explanatory power is given in the current month performance. That is somehow less useful than past performance data, but current performance is still observable within the month for the asset manager and investors in funds. Also, persistency of the performances of the fund, as it is indicated by the significance of 12 months past performance, may help asset managers to form some expectations about future outflows or inflows to the fund. Combined with previous short term flows we got some compact and easily observable variables that are explaining significant portion of fund flows.

Taking into account the obtained results, the question about how useful are those "global" explanatory variables that we calculated from merged fund data on particular funds, is still open. In previous literature authors haven’t put much attention to that question, but that was probably determined by the number of funds which data they were analyzing

In Tables 4-9 we present regression results with the same independent variables as in the last regression, but on data of each fund. We put those tables at the end of the document. As it can be seen from those results, some of the variables kept their significance, but importance of them are not uniform across different funds. Generally, current performance is found to be the best indicator of fund flows, while other variables are varying among funds. We find that the general level of the explanatory power of the presented regression model is satisfactory (average $R^{2}$ is 0.3707 ).

Besides the presented results, we tried various other regressions. Among those we included variables from the regression which results were presented in Table 2, but no significant improvement has been noted (average $R^{2}$ is 0.4073 ). Also, we couldn't find any obvious pattern among significance of the regression variables since it remained very unstable. It is important to note that in the case of that regression we couldn't use variables LowPerf, MidPerf and HighPerf, but we introduced another variable that measures relative performance of the funds. In order to compute the relative performance of funds relative to the benchmark, we first define the benchmark. We choose to follow the usual path in capital markets methodology and we defined the capital weighted benchmark. With notation as before, where $\operatorname{Perf}_{i, t}$ and $N A V_{i, t}, i=1, \cdots, 21$, denote performance of the i-th fund in month $\mathrm{t}$ and assets under management in i-th fund in month $\mathrm{t}$ respectively, then the benchmark in time thas value $B_{t}$ defined by

$$
B_{t}=\frac{\sum_{i=1}^{21} \operatorname{Perf} f_{i, t} \cdot N A V_{i, t}}{\sum_{i=1}^{21} N A V_{i, t}}
$$


Table 4. Regression for particular funds.

\begin{tabular}{ccccc}
\hline Independent variable & Aureus Eq & Erste Eq & Erste Bal & FIMA Eq \\
\hline Intercept & 0.1053 & 0.2687 & 0.1183 & 0.7412 \\
Performance $(\mathrm{t})$ & $(0.424)$ & $(0.356)$ & $(0.375)$ & $(0.080)$ \\
Performance 12 months & $0.2409^{*}$ & $0.6515^{* * *}$ & $0.4033^{*}$ & $0.9126^{*}$ \\
& $(0.026)$ & $(0.000)$ & $(0.038)$ & $(0.049)$ \\
Ln(NAV) & 0.0261 & 0.0646 & 0.0434 & 0.1281 \\
Flow in prev. month & $(0.200)$ & $(0.216)$ & $(0.313)$ & $(0.105)$ \\
& -0.0058 & -0.013 & -0.006 & -0.0400 \\
Flow in last 3 months & 0.1096 & $-0.348^{* *}$ & 0.101 & 0.1791 \\
& $(0.492)$ & $(0.008)$ & $(0.448)$ & $(0.166)$ \\
& 0.1293 & $0.2184^{* *}$ & $0.1414^{* *}$ & 0.0166 \\
Adjusted $\mathrm{R}^{2}$ & $(0.067)$ & $(0.003)$ & $(0.004)$ & $(0.7074)$ \\
\hline
\end{tabular}

Table 5. Regression for particular funds.

\begin{tabular}{ccccc}
\hline Independent variable & HI Bal & HI Growth & HPB Eq & HPB Dyn \\
\hline Intercept & $0.2305^{*}$ & 0.1445 & 0.2555 & 0.0815 \\
Performance (t) & $(0.047)$ & $(0.138)$ & $(0.439)$ & $(0.505)$ \\
Performance 12 months & $0.5695^{*}$ & $0.3756^{*}$ & $0.5909^{*}$ & $0.4738^{* * *}$ \\
Ln(NAV) & $(0.022)$ & $(0.020)$ & $(0.020)$ & $(0.001)$ \\
& $(0.447)$ & $(0.284)$ & $(0.061)$ & -0.011 \\
Flow in prev. month & -0.013 & -0.008 & -0.014 & -0.006 \\
& $(0.054)$ & $(0.155)$ & $(0.452)$ & $(0.392)$ \\
& $0.3002^{*}$ & 0.1873 & 0.2791 & -0.068 \\
Flow in last 3 months & $(0.018)$ & $(0.149)$ & $(0.058)$ & $(0.588)$ \\
& 0.0517 & $0.1166^{*}$ & -0.0350 & -0.0015 \\
& $(0.277)$ & $(0.017)$ & $(0.5962)$ & $(0.744)$ \\
\hline & 0.3331 & 0.4264 & 0.1858 & 0.2175 \\
\hline
\end{tabular}

Our new regression variable was then defined as performance relative to that benchmark in 6 month and 12 month time, i.e. Excess6 $6_{i, t}$ and Excess $12_{i, t}$ defined by

$$
\text { Excess }_{i, t}=\prod_{i=t-7}^{t-1}\left(1-\operatorname{Perf}_{i, t}\right)-\prod_{i=t-7}^{t-1}\left(1-B_{t}\right)
$$

for each fund and with obvious analogue for 12 months. It turned out that for some funds those variables were statistically significant, but again we couldn’t find a pattern in that process.

\section{Conclusions}

We wanted to test some results from previous literature on the relation between performance of funds and flows 
Table 6. Regression for particular funds.

\begin{tabular}{ccccc}
\hline Independent variable & HPB Glob & Ilirika Eq & KD Eq & OTP Bal \\
\hline Intercept & 0.4246 & 0.207 & -0.033 & 0.2425 \\
& $(0.136)$ & $(0.354)$ & $(0.739)$ & $(0.428)$ \\
Performance (t) & $0.5541^{*}$ & $0.7768^{* * *}$ & $0.3091^{* * *}$ & $0.437^{*}$ \\
& $(0.023)$ & $(0.000)$ & $(0.000)$ & $(0.043)$ \\
Performance 12 months & $0.1852^{* *}$ & $0.0798^{*}$ & 0.0039 & $0.1041^{*}$ \\
Ln(NAV) & $(0.002)$ & $(0.034)$ & $(0.799)$ & $(0.042)$ \\
& -0.022 & -0.011 & 0.002 & -0.013 \\
Flow in prev. month & -0.079 & -0.086 & $0.199^{*}$ & $0.4454^{* *}$ \\
& $(0.5848)$ & $(0.559)$ & $(0.020)$ & $(0.007)$ \\
Flow in last 3 months & -0.003 & 0.0875 & 0.0498 & -0.019 \\
& $(0.969)$ & $(0.206)$ & $(0.095)$ & $(0.718)$ \\
Adjusted $\mathrm{R}^{2}$ & 0.2848 & 0.5037 & 0.4496 & 0.3387 \\
\hline
\end{tabular}

Table 7. Regression for particular funds.

\begin{tabular}{cccc}
\hline Independent variable & PBZ Eq & PBZ Glob & PBZ Istock \\
\hline Intercept & 0.2393 & 0.1141 & 0.1664 \\
Performance (t) & $(0.222)$ & $(0.121)$ & $(0.621)$ \\
Performance 12 months & $0.3016^{* *}$ & $0.4206^{* * *}$ & $0.2802^{* *}$ \\
& $(0.006)$ & $(0.000)$ & $(0.003)$ \\
Ln(NAV) & 0.0025 & 0.0204 & 0.0093 \\
Flow in prev. month & $(0.928)$ & $(0.396)$ & $(0.640)$ \\
& -0.012 & -0.006 & -0.009 \\
Flow in last 3 months & $(0.219)$ & $(0.123)$ & $(0.606)$ \\
& -0.082 & 0.1418 & -0.216 \\
& $(0.591)$ & $(0.229)$ & $(0.236)$ \\
Adjusted $R^{2}$ & $0.2501^{* * *}$ & $0.1655^{* * *}$ & $0.2274^{*}$ \\
\hline
\end{tabular}

from them. We recovered some of those results on the Croatian fund data which we consider to be encouraging, since data are quite specific with long declining phase, and illiquid market.

We investigated several other explanatory variables and we showed that present month performance of the fund and persistency of past performances are the most significant among other variables that carry some information about fund performance. Additionally, we showed that the size of the fund is negatively related to flow data. This may be a consequence of relatively illiquid underlying markets. Also, we used the fact that past flows to funds showed some tendency of persistence and increased the explanatory power of the linear regression model.

Finally, in the analysis on fund level data, the usefulness of the introduced independent variables was shown, but universality of those variables for particular fund data is not straightforward. Their significance changes in 
Table 8. Regression for particular funds.

\begin{tabular}{cccc}
\hline Independent variable & RBA Bal & RBA Eq & ZB Aktiv \\
\hline Intercept & 0.2641 & 0.0230 & 0.0169 \\
Performance (t) & $(0.014)$ & $(0.876)$ & $(0.925)$ \\
Performance 12 months & $0.640^{* * *}$ & $0.3035^{* * *}$ & $0.5457^{* * *}$ \\
& $(0.000)$ & $(0.001)$ & $(0.000)$ \\
Ln(NAV) & 0.0392 & -0.0030 & 0.0275 \\
Flow in prev. month & $(0.1994)$ & $(0.888)$ & $(0.252)$ \\
& $-0.013^{*}$ & -0.001 & -0.001 \\
Flow in last 3 months & $(0.014)$ & $(0.862)$ & $(0.872)$ \\
& 0.0136 & $-0.2450^{*}$ & -0.040 \\
Adjusted $R^{2}$ & $(0.910)$ & $(0.042)$ & $(0.726)$ \\
& $0.1516^{* *}$ & $0.2307^{* * *}$ & 0.0203 \\
& $(0.003)$ & $(0.000)$ & $(0.577)$ \\
& 0.5354 & 0.5616 & 0.3549 \\
\hline
\end{tabular}

Table 9. Regression for particular funds.

\begin{tabular}{cccc}
\hline Independent variable & ZB Euro Eq & ZB Global & ZB Trend \\
\hline Intercept & $0.9454^{* * *}$ & 0.1325 & 0.4601 \\
Performance (t) & $(0.001)$ & $(0.232)$ & $(0.074)$ \\
Performance 12 months & -0.057 & 0.4151 & 0.3592 \\
Ln(NAV) & $(0.674)$ & $(0.055)$ & $(0.101)$ \\
& $(0.002)$ & 0.0808 & $0.2018^{* * *}$ \\
Flow in prev. month & $-0.049^{* * *}$ & $(0.090)$ & $(0.001)$ \\
& $(0.001)$ & -0.007 & -0.0250 \\
Flow in last 3 months & 0.054 & $(0.234)$ & $(0.067)$ \\
& $(0.716)$ & 0.1240 & -0.033 \\
& $0.1239^{*}$ & $(0.310)$ & $(0.7715)$ \\
& $(0.017)$ & $0.1217^{*}$ & 0.0378 \\
& 0.3931 & $(0.018)$ & $(0.411)$ \\
& & 0.2950 & 0.1292 \\
\hline
\end{tabular}

the case of different funds, although general level of their explanatory power is not decreasing when appropriate regressions on a particular fund data are applied.

For future research it would be interesting to check both the obtained results on other fund data and significance of cumulative measures of past flows and performances on present funds' flows. Also, more research is needed to check the stability of explanatory variables for particular fund data.

\section{References}

[1] Chevalier, J. and Ellison, G. (1997) Risk Taking by Mutual Funds as a Response to Incentives. Journal of Political Economy, 105, 1167-1200. http://dx.doi.org/10.1086/516389 
[2] Sirri, E.R. and Tufano, P. (1998) Costly Search and Mutual Fund Flows. The Journal of Finance, 53, 1589-1622. http://dx.doi.org/10.1111/0022-1082.00066

[3] Ippolito, R.A. (1992) Consumer Reaction to Measures of Poor Quality: Evidence from the Mutual Fund Industry. Journal of Law and Economics, 35, 45-70. http://dx.doi.org/10.1086/467244

[4] Spiegel, M. and Zhang, H. (2013) Mutual Fund Risk and Market Share-Adjusted Fund Flows. Journal of Financial Economics, 108, 506-528. http://dx.doi.org/10.1016/j.jfineco.2012.05.018

[5] Chen, Q., Goldstein, I. and Jiang, W. (2010) Payoff Complementarities and Financial Fragility: Evidence from Mutual Fund Outflows. Journal of Financial Economics, 97, 239-262. http://dx.doi.org/10.1016/j.jfineco.2010.03.016

[6] Huang, J.C., Wei, K.D. and Yan, H. (2012) Investor Learning and Mutual Fund Flows. In: AFA 2012 Chicago Meetings Paper.

[7] Ferreira, M.A., Keswani, A., Miguel, A.F. and Ramos, S.B. (2006) The Determinants of Mutual Fund Performance: A Cross-Country Study. Swiss Finance Institute Research Paper, 31 (last revised July 27, 2011).

[8] Podobnik, B., Balen, V., Jagric, T. and Kolanovic, M. (2007) Croatian and Slovenian Mutual Funds and Bosnian Investments Funds. Czech Journal of Economics and Finance, 57, 159-177.

[9] Cashman, G.D., Nardari, F., Deli, D.N. and Villupuram, S.V. (2012) Investor Behavior in the Mutual Fund Industry: Evidence from Gross Flows. Journal of Economics and Finance, April, 1-27. 
Scientific Research Publishing (SCIRP) is one of the largest Open Access journal publishers. It is currently publishing more than 200 open access, online, peer-reviewed journals covering a wide range of academic disciplines. SCIRP serves the worldwide academic communities and contributes to the progress and application of science with its publication.

Other selected journals from SCIRP are listed as below. Submit your manuscript to us via either submit@scirp.org or Online Submission Portal.
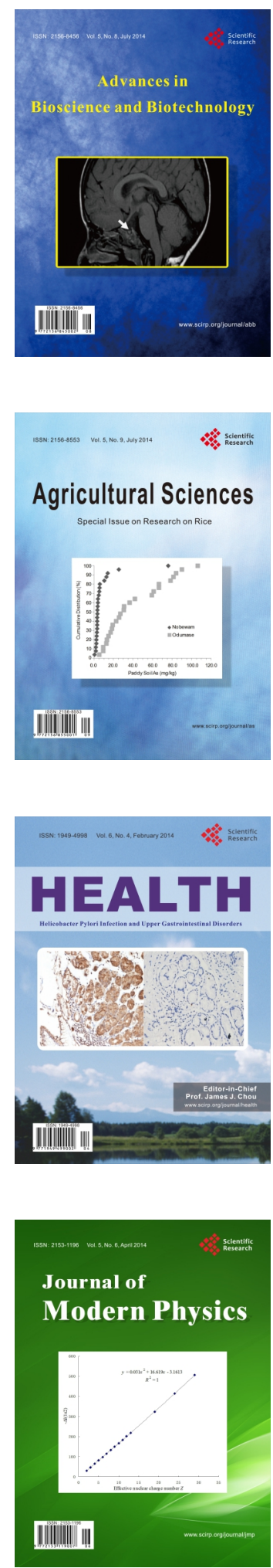
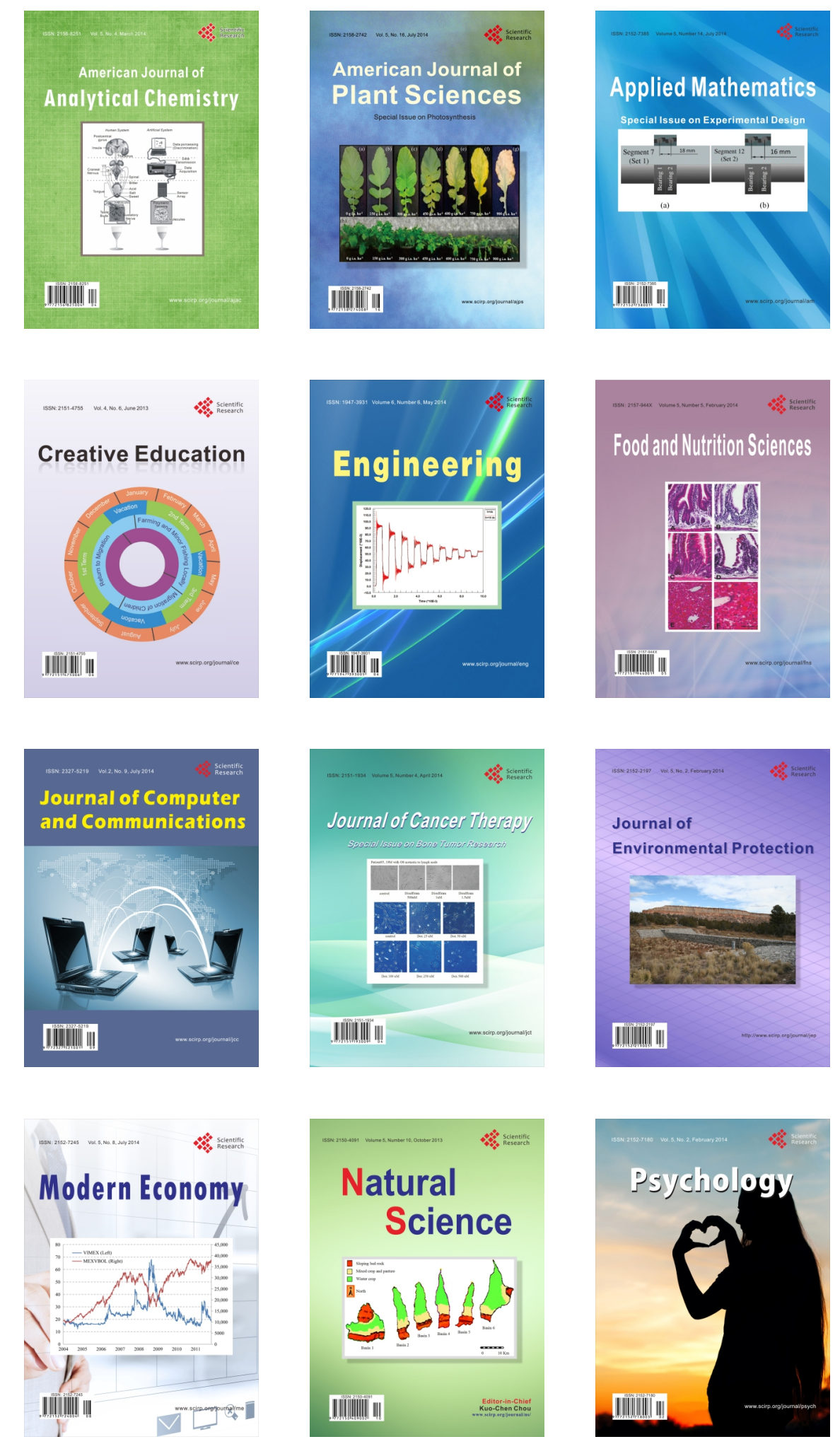